\title{
PREDICTION OF USER BEHAVIOUR ON THE BASIS OF KEY DETERMINANTS OF SUSTAINABILITY OF CONSTRUCTION PRODUCTS WITH THE HELP OF THE ANALYTIC HIERARCHY PROCESS
}

\begin{abstract}
The variety of construction products on the market makes a decision-making process complex. The main purpose of this study consists in identifying the relative importance of sustainability characteristics in selecting construction products, in particular, wall paints, by non-experts, i.e. private households. For this purpose, with the hypothesis that environmental and health safety have a high priority, an AHP model is used for a comparison of three alternative wall paints, designed in the Super Decisions Software.
\end{abstract}

Keywords: sustainability, wall paints, analytic hierarchy process, user behaviour.

\section{Introduction}

In general, private households use manifold criteria for their decision-making on construction products in general and of wall paints in particular. These include market prices and quality (as revealed in protection functions and durability), reparability, aesthetics, human health and environmental safety. The study investigates the significance of sustainability and human health within the decision-making.

\section{Literature Review}

The most authors concentrate their research efforts on the decision-making of sustainable construction products by experts. For example, Ogunkah et al. (2012) presented an AHP model for local and recycled building materials for an expert user. Similarly, Wahlström et al. (2014) describe the EU legislation criteria influencing the selection of construction products as of relevance for experts. Analogously, Dirlich (2011) compared various sustainability assessment schemes for construction products on a global level and in Germany. In contrast, this study focuses on decision-making by non-experts, such as private households. Research in this group has not been documented in literature.

\section{Hypotheses/Objectives}

The objective of the study consists in developing of decision-making model for construction products with the example of wall paints by non-experts. In that context, the hypothesis is made that environmental and health safety score very highly in comparison with product prices.

\section{Research Design/Methodology}

The methodological approach consists in the development of an AHP model in the Super Decisions Software, using various information sources on sustainability of wall paints. This is applied to three alternatives, known as Alpina Naturaweiss, Milk Paint, and Danish / Tung Oil. 
ISAHP Article: Prediction of User Behaviour on the Basis of Key Determinants of Sustainability for Construction Products with the Help of the Analytic Hierarchy Process.

\section{Data/Model Analysis}

The three alternatives were compared according to four criteria, (i) Benefits, (ii) Opportunities, (iii) Costs and (iv) Risks. The inconsistency indices for each pairwise comparison did not exceed 0.06948 , which is well below the critical value of 0.1 .

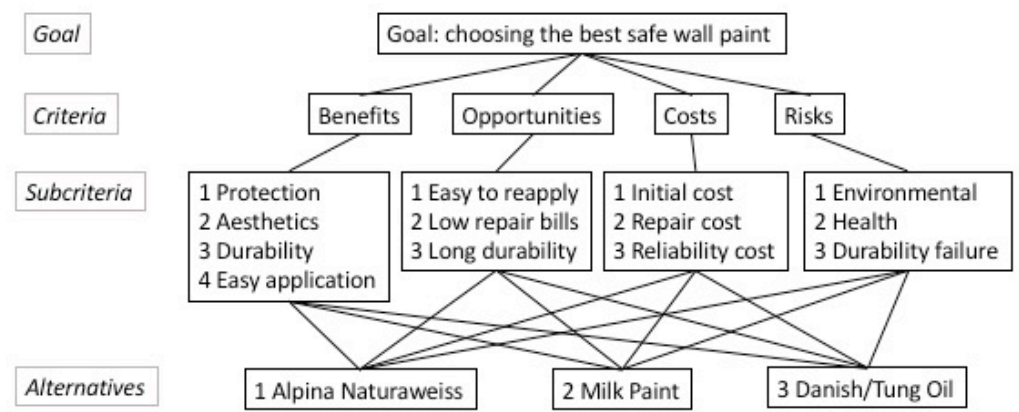

Fig. 1. Hierarchy of a BOCR model.

\begin{tabular}{|l|l|l|l|l|l|l|}
\hline & BENEFITS & $\begin{array}{l}\text { OPPORTUNITI } \\
\text { ES }\end{array}$ & COSTS & RISKS & $\begin{array}{l}\left(\mathrm{B}^{*} \mathrm{O}\right) /\left(\mathrm{C}^{*}\right. \\
\text { R) mult.for. }\end{array}$ & $\begin{array}{l}\mathrm{B}+1 / \mathrm{O}+1 / \mathrm{C} / \mathrm{R} \\
\text { add.for. }\end{array}$ \\
\hline 1Alpina Naturaweiss & 0.200 & 0.105 & 0.100 & 0.277 & 0.506 & 0.408 \\
\hline 2Milk Paint & 0.133 & 0.144 & 0.316 & 0.081 & 0.029 & 0.138 \\
\hline 3Danish/Tung Oil & 0.167 & 0.252 & 0.083 & 0.142 & 0.464 & 0.454 \\
\hline
\end{tabular}

Fig. 2. Overall synthesized priorities for all the alternatives combined in the top-level network in two ways.

\section{Limitations}

The outcome of the AHP model has been based on the hypothesis that environmental and health safety scores high above product prices. Hence, adding outcomes from a survey about the actual assessment of these characteristics by non-experts, i.e. private households, will lead to a better understanding of the decision-making process.

\section{Conclusions}

The study has revealed that the design of an AHP model with a high priority of the sustainability characteristics of construction products, in particular wall paints, leads to a meaningful comparison of alternative products. As next, the model will be extended by the real world assessments of these priorities by non-experts.

\section{Key References}

Dirlich, S. (2012). Integration der Bestandsqualität in die Zertifizierung von Gebäuden. IÖR Schriften Band 55, Dresden, 220.

Ogunkah, I., \& Yang, J. (2012). Investigating Factors Affecting Material Selection: The Impacts on Green Vernacular Building Materials in the Design-Decision Making Process. Buildings2012, 2, 1-32.

Wahlström, M., Laine-Zlijoki, J., Järnström, Kaartinen, T., Erlandsson, M., Cousins, A. P., Wik, O., Suer, P., Oberender, A., Hjelmar, O., Birgisdottir, H., Butera, S., Astrup, T. F., Jørgensen A. (2014). Environmentally Sustainable Construction Products and Materials - Assessment of release and emissions. Nordic Innovation Publication 2014:3. 